\title{
Correction to: Development of capillary-paper spray for small-molecule analysis in complex samples
}

\author{
Chaozi Liu ${ }^{1,2} \cdot$ Yuze $\mathrm{Li}^{1,2} \cdot$ Caiqiao Xiong ${ }^{1} \cdot$ Zongxiu Nie $^{1,3}$ \\ Received: 16 March 2021 / Accepted: 16 March 2021 / Published online: 26 March 2021 \\ (C) Springer-Verlag GmbH Germany, part of Springer Nature 2021
}

\section{Correction to: Analytical and Bioanalytical Chemistry https://doi.org/10.1007/s00216-020-03072-y}

The authors would like to call the reader's attention to the fact that, unfortunately, there was a mistake in the order of the affiliations of all authors. Please find the correct information below:

Chaozi Liu, ${ }^{\text {a, b }}$ Yuze Li, ${ }^{\text {a, b }}$ Caiqiao Xiong, ${ }^{\text {a }}$ Zongxiu Nie ${ }^{\text {*a, c }}$

a. Beijing National Laboratory for Molecular Sciences, Key Laboratory of Analytical Chemistry for Living Biosystems, Institute of Chemistry, Chinese Academy of Sciences, Beijing, 100190, China.

b. University of the Chinese Academy of Sciences, Beijing, 100049, China

c. National Centre for Mass Spectrometry in Beijing, Beijing, 100190, China.

Publisher's note Springer Nature remains neutral with regard to jurisdictional claims in published maps and institutional affiliations.

The online version of the original article can be found at https://doi.org/ 10.1007/s00216-020-03072-y

\footnotetext{
Caiqiao Xiong

xiongcq@iccas.ac.cn

$\triangle$ Zongxiu Nie

znie@iccas.ac.cn

1 Beijing National Laboratory for Molecular Sciences, Key Laboratory of Analytical Chemistry for Living Biosystems, Institute of Chemistry, Chinese Academy of Sciences, Beijing 100190, China

2 University of the Chinese Academy of Sciences, Beijing 100049, China

3 National Centre for Mass Spectrometry in Beijing, Beijing 100190, China
} 